\title{
Volatility Research of Shanghai Stock Market Based on GARCH Model Family
}

Donghui Iv ${ }^{1, a}$

${ }^{1}$ Department of Mathematics and Physics, University of Science and Technology Beijing 30 Xueyuan Road, Beijing, 100083, China

a290932317@qq.com

Keywords: volatility, GARCH family model, empirical analysis, time series analysis

Abstract. We made statistical analysis of the income sequence of the Shanghai stock market from 2013.1.4 to 2016.12.30 using EVIEWS7.2 and matlabR2013b. We found that the income series have excess kurtosis and heteroscedasticity, and the distribution of series data is not normal distribution. There is obvious ARCH effect and fluctuation aggregation effect in the series, but the leverage effect is not obvious. Some changes and new features have appeared in the stock market of China.

\section{Introduction}

Volatility research is the core of the research about financial market because it represents the uncertainty about gains and losses as well as the risk of the financial market. Volatility is also the focus of the securities sector and investors. So research in volatility is very important. The stock market of china experienced the immature period, during which skyrocketing and slump even disaster is frequent. As time went by, our stock market become more and more mature and normative. In recent years, the development of our economic is fast and steady. What interest us are questions that whether some new features our stock market have developed and that which model is more suitable to be used in the research.

\section{Basic Statistics of Closing Price and Income Sequence}

We count the closing price from 2012.1.4 to 2016.12.30 of shanghai stock market, with the total of 1214 data. We calculate the income with formula (1) and we draw Fig.1 to have a basic impression of the closing price and income sequence.

$$
r_{t}=\ln p_{t}-\ln p_{t-1}
$$

In which, $p_{t}$ is the closing price of date $t$ and $r_{t}$ is the income.

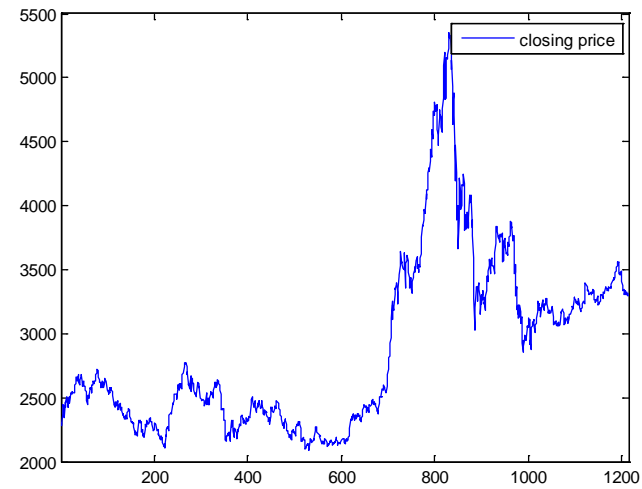

Fig. 1 The change of closing price

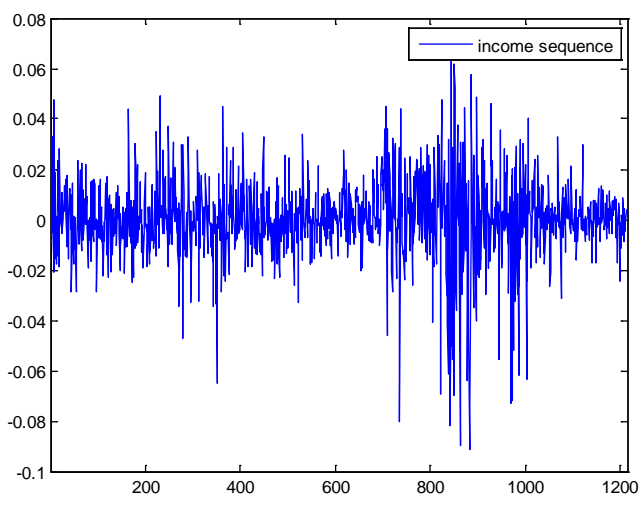

Fig. 2 The change of income 
Some basic statics of income sequence are shown in Table 1.

Table 1 Basic statics of income sequence

\begin{tabular}{|c|c|c|c|}
\hline Mean & 0.029673 & Kurtosis & 8.14341 \\
\hline Median & 0.03619 & Jarque-Bera & 1467.911 \\
\hline Maximum & 6.498852 & Probability & 0 \\
\hline Minimum & -9.1542 & Sum & 36.0225 \\
\hline Std. Dev. & 1.634189 & Sum Sq. Dev. & 3239.406 \\
\hline Skewness & -0.80078 & Observations & 1214 \\
\hline
\end{tabular}

As we can see from Table 1,the variance of income is small while it's kurtosis is large.That is to say the distribution of income have excess kurtosis and strong volatility, and much extreme value exist in shanghai stock market. From Jarque-Bera and it's Probability statistic, we think that the income series is disobedient to normal distribution.In addition, we think the number of the days that the income is lower than it's mean is lager than the income is higher because the skewness is smaller than zero.

\section{Stability Test of Income Sequence}

We draw the self - correlation graph and partial correlation graph of the income sequence in Fig.3
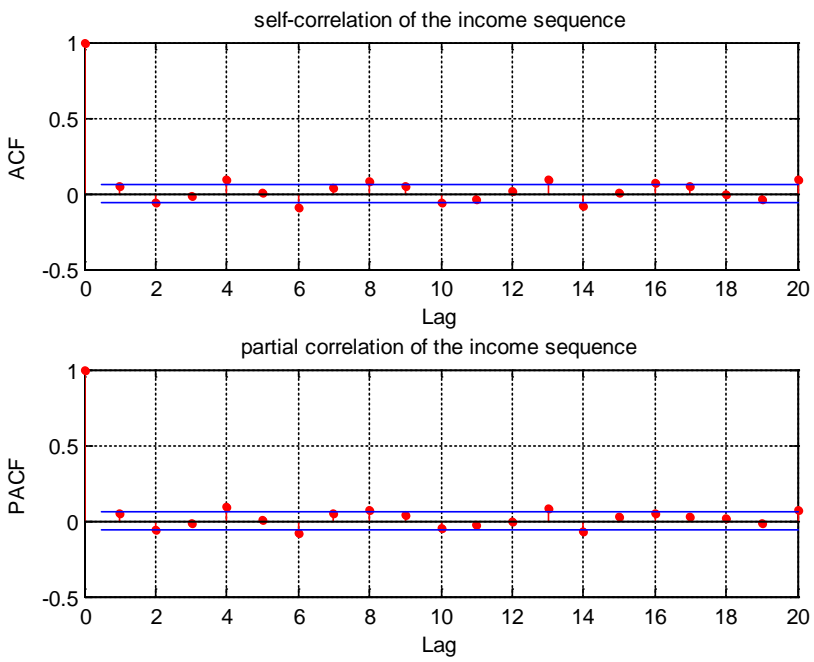

Fig. 3 the self - correlation and partial correlation graph of income sequence

As is shown from Fig. 3,the ACF and PACF of income series is smaller than 0.05 when the lag is larger than 1.So we can basically conclude that the income sequence is stationary.For futher proof,we did the ADF test.The output of Eviews7.2 is shown in Table 2.

Table 2 the output of ADF test

\begin{tabular}{lccc}
\hline \hline & t-Statistic & Prob.* $^{*}$ \\
\hline \hline Augmented Dickey-Fuller test statistic & -33.16208 & 0.0000 \\
\hline Test critical values: & 1\% level & -3.435527 & \\
& 5\% level & -2.863714 & \\
$10 \%$ level & -2.567978 & \\
\hline \hline
\end{tabular}


From the table, we can see that t-statistics of ADF have reached -33 and we refused the null hypothesis at $1 \%$ level. So we think the income sequence is stationary.

\section{ARCH Effect Test}

We draw the self - correlation graph and partial correlation graph of the income square series in Fig.4
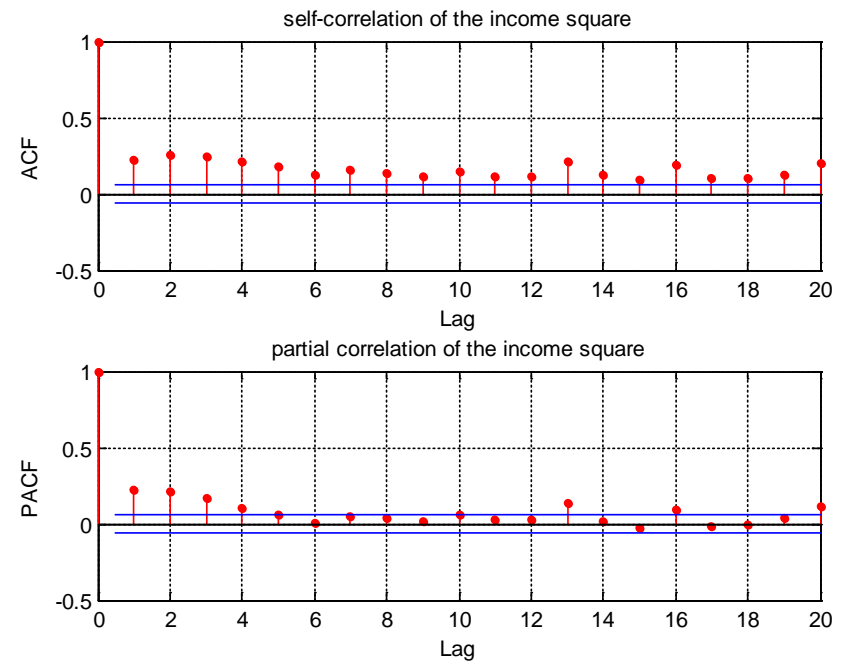

Fig. 4 the self - correlation and partial correlation graph of income square

We can see that the ACF is obviously lager than the standard even the lag is 20 and that the PACF become smaller than 0.05 after the lag is more than 4 from Fig. 5 . We think that the income square series is non-stationary while the income series is stationary. So we can conclude that ARCH effect exists in the income sequence.

For more proof, we did the LM test. We can see that the p value of LM is almost zero when the lag is larger than 2. Our conclusion is proofed once again. So it's reasonable to measure the volatility of the stock market by GARCH model family.

\section{Empirical Analysis Based on GARCH Model}

First, in order to confirm the order of the GARCH model, we establish GARCH(1,1), GARCH(1,2), and so on.

Table 4 different index of different GAECH model

\begin{tabular}{|c|c|c|c|c|}
\hline & AIC & SC & $\begin{array}{c}\text { Log } \\
\text { likelihood }\end{array}$ & $\begin{array}{c}\text { whether coefficients } \\
\text { are all significant }\end{array}$ \\
\hline GARCH(1,1) & 3.524964 & 3.537571 & -2136.653 & YES \\
\hline GARCH(1,2) & 3.525606 & 3.542416 & -2136.043 & No \\
\hline GARCH(1,3) & 3.523867 & 3.544879 & -2133.987 & YES \\
\hline GARCH(2,1) & 3.520714 & 3.537524 & -2133.073 & YES \\
\hline GARCH(2,2) & 3.521865 & 3.542877 & -2132.772 & No \\
\hline GARCH(2,3) & 3.522281 & 3.547495 & -2132.024 & No \\
\hline GARCH(3,1) & 3.521428 & 3.542440 & -2132.507 & No \\
\hline GARCH(3,2) & 3.521682 & 3.546896 & -2131.661 & No \\
\hline GARCH(3,3) & 3.522348 & 3.551765 & -2131.065 & No \\
\hline
\end{tabular}

Among the three GARCH model whose coefficients are all significant, we can see that their AIC and SC are almost equal. So we think the GARCH(1,1) model is best because it's Log likelihood is obviously smaller than the other two. 
The output of GARCH(1,1) by Eviews7.2 is shown in Table 5.

Table 5 The output of GARCH(1,1) by Eviews7.2

\begin{tabular}{ccccc}
\hline \hline Variable & Coefficient & Std. Error & z-Statistic & Prob. \\
\hline \hline \multicolumn{5}{c}{ Variance Equation } \\
\hline C & 0.016018 & 0.005326 & 3.007664 & 0.0026 \\
RESID $(-1)^{\wedge} 2$ & 0.057373 & 0.006457 & 8.885524 & 0.0000 \\
GARCH(-1) & 0.936388 & 0.006160 & 152.0062 & 0.0000 \\
\hline \hline
\end{tabular}

So we establish the GARCH(1,1) model as formula (2)

$$
\begin{aligned}
& r_{i}=0.029673+\varepsilon_{t} \\
& \sigma_{t}^{2}=0.016018+0.057373 \varepsilon_{t-1}^{2}+0.936388 \sigma_{t-1}^{2}
\end{aligned}
$$

We can calculate that $\alpha_{1}+\beta_{1}=0.993761$. The data is almost 1 . That is to say that fluctuation aggregation effect obviously exists in the income sequence and persistence of external shock is obvious.

Residual of the model is shown in Fig. 5 as well as correlation of residual is shown in Table 6.

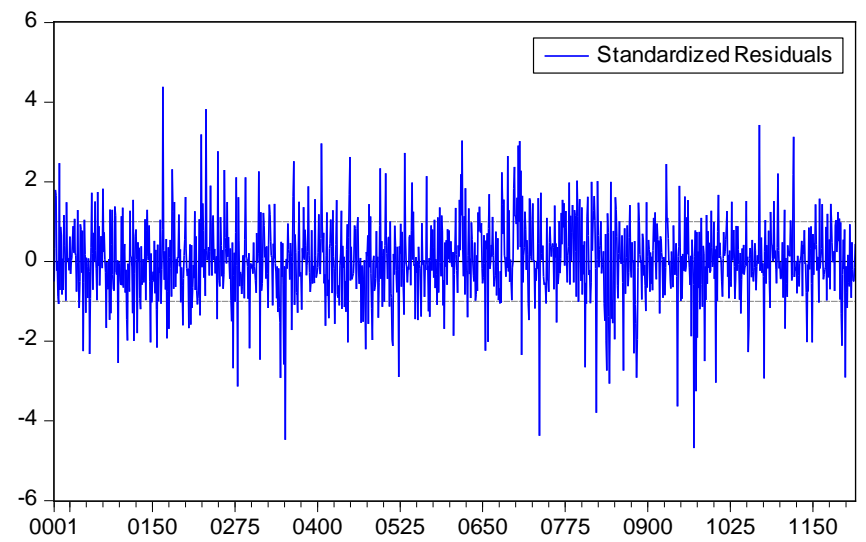

Fig. 5 residual sequence of GARCH(1,1) model

Table 6 corelogram of residuals and residuals squared

\begin{tabular}{|r|r|r|r|r|r|r|r|}
\hline \multicolumn{3}{|c|}{ corelogram of stadardized residuals } & \multicolumn{3}{|c|}{ corelogram of stadardized residuals squared } \\
\hline AC & PAC & Q-Stat & Prob & \multicolumn{1}{c|}{ AC } & \multicolumn{1}{c|}{ PAC } & Q-Stat & Prob \\
\hline 0.041 & 0.041 & 2.0803 & 0.149 & -0.038 & -0.038 & 1.7568 & 0.185 \\
\hline-0.001 & -0.005 & 5.7204 & 0.334 & 0.001 & -0.001 & 4.0394 & 0.544 \\
\hline 0.027 & 0.028 & 15.709 & 0.108 & 0.01 & 0.011 & 13.26 & 0.209 \\
\hline 0.013 & 0.016 & 17.098 & 0.313 & -0.044 & -0.037 & 17.528 & 0.288 \\
\hline 0.04 & 0.031 & 30.661 & 0.201 & 0.046 & 0.043 & 24.135 & 0.237 \\
\hline
\end{tabular}

Annotations: the lags are 1,5,10,15,20.

We think that there is no significant correlation in the stadardized residual and stadardized residual squared sequence as Table 6 shows. So we think the simulation result is satisfactory.

In addition, the conditional variance estimation sequence given by GARCH(1,1) is shown in Fig. 6. 


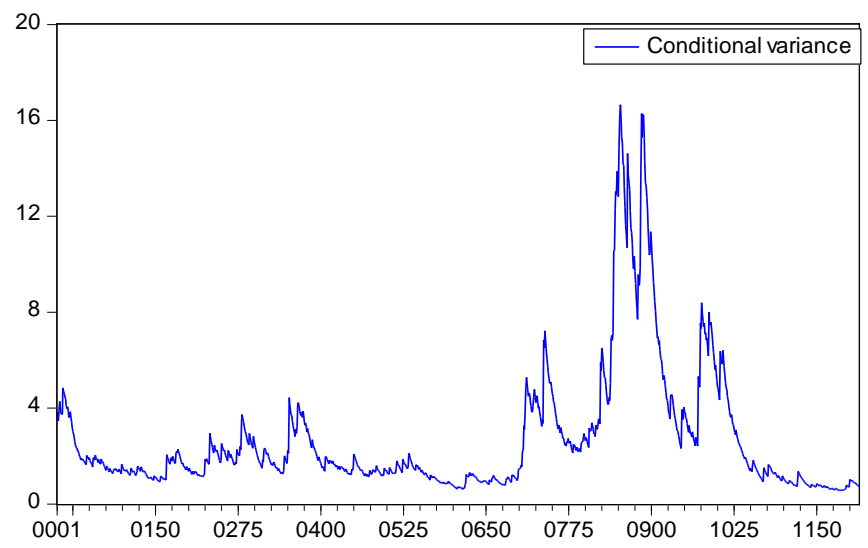

Fig. 6 conditional variance given by GARCH(1,1) model

As we can see from Fig. 6, the conditional variance is large when the volatility is strong while conditional variance is small relatively when the volatility is weak. So we think that the model captured the fluctuation aggregation phenomenon.

\section{Empirical Analysis Based on Other Generalized GARCH Models}

The GARCH(1,1)-M model output by Eviews7.2 is shown in Table 7.

Table 7 GARCH(1,1)-M model output by Eviews7.2

\begin{tabular}{ccccc}
\hline \hline Variable & Coefficient & Std. Error & z-Statistic & Prob. \\
\hline \hline @SQRT(GARCH) & 0.028731 & 0.028292 & 1.015524 & 0.3099 \\
\hline \hline & \multicolumn{4}{c}{ Variance Equation } \\
C & 0.016083 & 0.005545 & 2.900470 & 0.0037 \\
RESID(-1)^2 & 0.057794 & 0.006511 & 8.876348 & 0.0000 \\
GARCH(-1) & 0.936016 & 0.006172 & 151.6542 & 0.0000 \\
\hline \hline
\end{tabular}

As we can see from Table 7, the coefficient of $\sigma_{t}^{2}$ in mean equation is not significant. So we think that the change of volatility have no obvious effect on income.

The TGARCH(1,1), EGARCH(1,1) model output by Eviews7.2 is shown in Table 8 and Table 9.

Table 8 TGARCH(1,1) model output by Eviews7.2

\begin{tabular}{|c|c|c|}
\hline Variable & Coefficient Std. Error z-Statistic & Prob. \\
\hline & \multicolumn{2}{|l|}{ Variance Equation } \\
\hline $\mathrm{C}$ & 0.0170130 .0054733 .108579 & 0.0019 \\
\hline $\operatorname{RESID}(-1)^{\wedge} 2$ & 0.0551230 .0076927 .166178 & 0.0000 \\
\hline $\operatorname{RESID}(-1)^{\wedge} 2^{*}(\operatorname{RESID}(-1)<0)$ & 0.0061840 .0090070 .686534 & 0.4924 \\
\hline GARCH(-1) & $0.9351690 .006201 \quad 150.7974$ & 0.0000 \\
\hline
\end{tabular}


Table 9 EGARCH(1,1) model output by Eviews7.2

\begin{tabular}{crrrr}
\hline \hline Variable & Coefficient & Std. Error & z-Statistic & Prob. \\
\hline \hline \multicolumn{6}{c}{ Variance Equation } \\
\hline C(1) & -0.091403 & 0.008724 & -10.47733 & 0.0000 \\
$\mathrm{C}(2)$ & 0.131608 & 0.012178 & 10.80676 & 0.0000 \\
$\mathrm{C}(3)$ & -0.007043 & 0.007114 & -0.989967 & 0.3222 \\
$\mathrm{C}(4)$ & 0.992611 & 0.002607 & 380.6757 & 0.0000 \\
\hline \hline
\end{tabular}

As we can see, the coefficient of $\sigma^{2}$ when external shock is negative is not significant. That is to say, leverage effect doesn't obviously exist in the stock market in recent years. This feature is different from that of previous years. Some new features and new changes have appeared in the stock market of our country.

The reasons resulting in the new phenomenon we infer are as follows:

(1) Good economic development prospects of our country.

(2) Our confidence's increasing of the stock market.

(3) Effective control of the stock market by government.

(4) Significantly rise of stock price from 2014 to 2015.

\section{Conclusion}

By modeling and analyzing, we found that ARCH effect obviously exists in Shanghai stock market and GARCH $(1,1)$ is the best model to measure the volatility. The influence of external shock lasts for a long time and fluctuation aggregation effect is obviously. But what is different from the past is that the leverage effect is not obvious and T-GARCH and EGARCH model are not suitable to be used in the research of the volatility of the stock market in recent years. That is to say the influence negative shock is not obviously stronger than positive shock. Maybe, it's the symmetry resulting in the phenomenon that income doesn't obviously connect with volatility. We think that some new features our stock market have developed.

\section{References}

[1] Haitao Pan and Xiaoni Wen: Application of Time Series Methods on Stock Volatility---MCMC Methods on the Estimation of Parameters of GARCH model(2009.1).

[2] Daimin Shi and Xiaoyan Xie: Applied Time Series Analysis, Higher Education Press(2011.6).

[3] Guangrong Tong and Yao He: Econometrics, Wuhan University Press(2008.6).

[4] Xiaofeng Tang and Zhiqiang Zhang:Empirical Analysis on the Volatility of Shanghai Stock Merket by GARCH model family(2008.10)

[5] Information on http://www.sse.com.cn/market/overview/ 